\title{
Heterosexual College Students Who Hookup with Same-Sex Partners
}

By: Arielle Kuperberg and Alicia M. Walker

Kuperberg, Arielle and Alicia M. Walker. 2018. "Heterosexual College Students Who Hookup with Same-Sex Partners." Archives of Sexual Behavior, 47(5): 1387-1403.

\section{This is a post-peer-review, pre-copyedit version of an article published in Archives of Sexual Behaviors. The final authenticated version is available online at: http://dx.doi.org/10.1007/s10508-018-1194-7.}

\begin{abstract}
:
Individuals who identify as heterosexual but engage in same-sex sexual behavior fascinate both researchers and the media. We analyzed the Online College Social Life Survey dataset of over 24,000 undergraduate students to examine students whose last hookup was with a same-sex partner ( $\mathrm{N}=383$ men and 312 women). The characteristics of a signifcant minority of these students ( $12 \%$ of men and $25 \%$ of women) who labelled their sexual orientation "heterosexual" difered from those who selfidentifed as "homosexual," "bisexual," or "uncertain." Diferences among those who identifed as heterosexual included more conservative attitudes, less prior homosexual and more prior heterosexual sexual experience, features of the hookups, and sentiments about the encounter after the fact. Latent class analysis revealed six distinctive "types" of heterosexually identifed students whose last hookup was with a same-sex partner. Three types, comprising $60 \%$ of students, could be classifed as mostly private sexual experimentation among those with little prior same-sex experience, including some who did not enjoy the encounter; the other two types in this group enjoyed the encounter, but difered on drunkenness and desire for a future relationship with their partner. Roughly, $12 \%$ could be classifed as conforming to a "performative bisexuality" script of women publicly engaging in same-sex hookups at college parties, and the remaining $28 \%$ had strong religious practices and/or beliefs that may preclude a non-heterosexual identity, including $7 \%$ who exhibited "internalized heterosexism." Results indicate several distinctive motivations for a heterosexual identity among those who hooked up with same-sex partners; previous research focusing on selective "types" excludes many exhibiting this discordance.
\end{abstract}

Keywords: Hookups | Same-sex sexual behavior | Sexual identity | Internalized heterosexism

\section{Article:}

\section{Introduction}

Many people engage in same-sex sexual encounters or desire them but maintain a heterosexual identity; others who adopt a lesbian, gay, bisexual (LGB) or other sexual minority identity later relinquish it for a heterosexual one (Diamond, 2003; Hamilton, 2007; Walker, 2014a, 2014b; Ward, 2015). One study of college students found $30 \%$ of women and $19 \%$ of men who identified as heterosexual reported same-sex attraction (Hoburg, Konik, Williams, \& Crawford, 2004). A study representative of $18-26$ year olds in the U.S. found $3 \%$ of men and $11 \%$ of 
women identified as "mostly heterosexual" when given that option, and same-sex attraction was reported by $5 \%$ of men and $13 \%$ of women, but only $2 \%$ of men and $4 \%$ of women identified as LGB (Savin-Williams \& Ream, 2007). Another study representative of U.S. 15-44 year olds found $9 \%$ of women and $3 \%$ of men who identified as heterosexual had same-sex sexual experience (Chandra, Copen, \& Mosher, 2013).

Several theoretical frameworks have been proposed to explain this discordance. Some studies with limited samples examined "the closet" or "the down low" (Boykin, 2005; Ford, Whetten, Hall, Kaufman, \& Thrasher, 2007; King, 2004; Phillips, 2005). Others focused on college "hookup culture" and expectations of sexual experimentation, including young women hooking up with other women at parties, ostensibly to attract men (Diamond, 2005; Kimmel \& Plante, 2002; Kuperberg \& Padgett, 2015; Wade, 2017; Ward, 2015). A third line of research examined LGB identity acquisition (Cass, 1979, 1996; Horowitz \& Newcomb, 2002; Kaufman \& Johnson, 2004). Negative feelings about homosexuality among those with same-sex attractions or "internalized heterosexism" may also be a factor (Kaufman \& Johnson, 2004; Taylor, 1999). We examined whether a heterosexual identity among these students correlated with characteristics that would be predicted by these distinct and sometimes-competing frameworks, and the extent to which students comprised distinguishable groups described by these theories.

\section{Same-Sex Hookups Among Self-Identified Heterosexuals}

Public fascination with self-identified heterosexuals hooking up with same-sex partners arose in the 1990s, along with phrases "on the down low" and "on the D.L." Originating among AfricanAmericans, these idioms originally referred to any act done secretly, but became associated with men who "publicly present as heterosexual while secretly having sex with other men" (Boykin, 2005; Ford et al., 2007; Phillips, 2005). Others used "in the closet" to describe LGB individuals hiding their sexual identity in public, or even to themselves (Seidman, Meeks, \& Traschen, 1999). Academic literature opted for "men who have sex with men" or "MSM," a term potentially obscuring the meaning-making of sexuality (Young \& Meyer, 2005).

Research on same-sex sexual encounters is generally limited and subject to sample bias. Some examined risk-taking and sexual activity in same-sex hookups from a larger sample, but most research focused on select groups, such as couples in long-term relationships or those identifying as LGB (Eisenberg, 2001; Kuperberg \& Padgett, 2015, 2017; Peplau \& Fingerhut, 2007; Rust, 1992). Past research also mostly focused on men and recruited subjects from biased sources, including websites, bars, or parks known to be frequented by MSM or LGBT organizations and magazines (Brady \& Busse, 1994; CDC, 2010; Cole, Kemeny, Taylor, \& Visscher, 1996; Hightow et al., 2006; Kaufman \& Johnson, 2004; Koblin et al., 2000; Lindley, Nicholson, Kerby, \& Lu, 2003; Rhodes, DiClemente, Cecil, Hergenrather, \& Yee, 2002; Rosario, Schrimshaw, Hunter, \& Braun, 2006; Rowen \& Malcolm, 2002). Much research on self-identified heterosexuals hooking up with same-sex partners focused on African-American men, despite White men more commonly exhibiting this disparity (Bleich \& Taylor-Clark, 2005; Ford et al., 2007; King, 2004; Ross, Essien, Wiliams, \& Fernandez-Esquer, 2003; Ward, 2015). This focus may stem from perceptions that "the down low" is limited to African- American men due to the origins of the term or heightened surveillance of the sexuality of men of color (Ward, 2015). 
Women also seek out same-sex sexual partners while identifying as heterosexual (Walker, 2014a, b), although research on students included only small samples of 80 or fewer (Diamond, 2003; Hamilton, 2007; Peterson \& Gerrity, 2006), and research outside of college contexts is even more limited. Walker (2014a) found women married to men who had affairs with women felt these encounters "didn't count" in terms of monogamy. While reporting lifelong same-sex attraction and sexual encounters, they rejected a bisexual identity, instead explaining these acts as due to their "freakiness," which they felt was the accurate term for their sexual orientation (Walker, 2014b). Budnick (2016) found women with the least education reported the most lifetime same-sex sexual events, but for some early entry into motherhood closed-off sexual exploration and possible development of a LGBQ identity.

\section{College Hookup Scripts and Same-Sex Hookups Among Heterosexuals}

Recent literature examined college hookups, casual sexual encounters which most college students participate in, that can range from an intense "make-out" session to intercourse (Bogle, 2008; England, Shafer, \& Fogarty, 2008; Kuperberg \& Padgett, 2015, 2016; Reiber \& Garcia, 2010). Hookup rates and risk-taking during hookups have been found to differ by gender, GPA, race, religiosity, mother's education, and age (Kuperberg \& Padgett, 2015, 2016, 2017). The college hookup scene is an opportunity for students to experiment with and affirm non-heterosexual sexual identities or to confirm a heterosexual one (Rupp, Taylor, Regev-Messalem, Fogarty, \& England 2013). Social "scripts," or expectations of behavior, position college as a "time to experiment" sexually (Kuperberg \& Padgett, 2015; Simon \& Gagnon, 2003) and may encourage same-sex hookups even among those without same-sex attractions. Many dismiss these hookups as "experimentation" or "accidental" (Ward, 2015).

Some women engage in same-sex hookups to attract men's attention as an established part of the college hookup "sexual script" (Diamond, 2005; Wade, 2017). Women often conduct this "performative bisexuality" in public spaces for the benefit of a male audience, as it is a commonly reported "turn-on" for heterosexual men (Kimmel \& Plante, 2002). Hamilton (2007) described a campus culture where heterosexually-identified women engaged in same-sex erotic behavior during parties, later posting the pictorial evidence to social media. Often attributed to alcohol consumption, these encounters included kissing and fondling breasts or buttocks, but no genital contact, and allowed young women to mark themselves as "edgy" (Hamilton, 2007).

However, suggesting that women engage in this behavior only to attract men may obscure some functions of these encounters. In one study, two female roommates reported dancing naked together when they were alone in their room, but jokingly dismissed it as an activity for "when they were bored," while another study found women dismissing private same-sex hookups as a result of inebriation (Hamilton, 2007; Wade, 2017). Hooking up with other women at alcohol-fueled public parties allowed women, particularly those who had negative views of lesbianism, to experiment with socially acceptable same-sex behavior assumed to be intended for male pleasure (Hamilton, 2007; Wade, 2017; Ward, 2015).

Other research focused on college men having sexual contact with men in "heterosexual contexts," per established social scripts, including fraternity hazing rituals culturally defined as heterosexual bonding activities rather than homosexual acts (Sanday, 2007; Silva, 2017; Simon \& Gagnon, 1986, 2003; Ward, 2015). Members of organizations present these as rituals of domination and humiliation aimed at increasing male bonding, and frame participants as having "no choice but to comply," creating a context for homosexual encounters contextualized as 
"obviously not gay," while permitting sexual flexibility and experimentation among men (Ward, 2015). These hazing encounters and other encounters described as "situational" homosexuality among men in specific contexts (such as in prisons) are not presumed to be significant to underlying sexuality (Kimmel, 2008; Ward, 2015).

\section{Sexual Identity Theory}

While questions of sexual orientation aim to categorize sexual attractions, desires, and behaviors, disparities between reported orientations and behavior suggest these questions instead measure sexual identity. Identity theory understands identities as a set of meanings individuals use to self-define what it means to be in a particular role or situation, but which are malleable and can change over an individual's lifetime (Rupp et al., 2013). Commitment to, acceptance, and integration of an LGB identity is an ongoing process often lasting through adolescence and beyond, with many first adopting a bisexual identity before later adopting a gay or lesbian identity (Rosario et al., 2006). Individuals sometimes adopt identities to represent current sexual partnerships or choices, rather than to embody their overall feelings of attraction to members of either gender over their lifetime (Seidman et al., 1999). Some lesbian and bisexual women later relinquish their sexual minority identity for a heterosexual one after forming relationships with men, to reconcile their identity and behavior (Diamond, 2003). Others describe their identity as "heteroflexible," meaning they are mostly attracted to men, but occasionally participate in same-sex sexual behaviors they may describe as random, accidental, or meaningless (Ward, 2015).

The "developmental stages model" theory of sexual identity positioned taking on a homosexual identity and integrating it into your broader personal identity as the final stage in becoming aware of one's underlying or "real" sexual orientation (Cass, 1979, 1996; Horowitz \& Newcomb, 2002; Kaufman \& Johnson, 2004). Researchers initially described the stages as (1) feelings of homosexual attraction and identity confusion; (2) homosexual experiences; (3) disclosing identities to some; and (4) sexual identity fully integrated into broader identity (Kaufman \& Johnson, 2004). An updated model later took the focus away from homosexual experiences, with stages including (1) identity confusion; (2) evaluating familial and social consequences of an LGB identity; (3) beginning to tolerate an LGB identity; (4) acceptance of identity, identifying to others, increasing contact with other LGB individuals; (5) developing pride for identity, perhaps anger toward society and heterosexuals; and (6) synthesizing an LGB identity with other aspects of identity (Cass, 1996). During early stages, individuals may attempt to reconcile a heterosexual identity with same-sex sexual behavior and attractions by interpreting them as temporary or a "special case" ("If not for this special person whom I love, I would be heterosexual") (Cass, 1996). They may later adopt a LGB identity or may cease that behavior and never adopt an LGB identity (Brady \& Busse, 1994; Cass, 1996; Horowitz \& Newcomb, 2002; Kaufman \& Johnson, 2004). They may be in "transition," where they have begun to "recognize that they are not heterosexual, yet have not adopted a homosexual identity" (Taylor, 1999). One study of college women found of those identified as being in one of the stages of homosexual identity development, those with "heterosexual" identities were all in Stages 1-3 of the updated model (Peterson \& Gerrity, 2006).

Researchers critiqued the developmental stages model as stemming from an essentialist perspective, with sexual identity conceptualized as unchanging (Horowitz \& Newcomb, 2002; Kaufman \& Johnson, 2004; Peterson \& Gerrity, 2006). Social constructionists instead 
conceptualized identity as fluid over time and social context, influenced by interactions that socially create and reinforce that identity, and personal and social significance at a specific time and place (Horowitz \& Newcomb, 2002). Indeed, the idea that same-sex sexual behaviors constitute an "identity" only fully emerged in the mid-twentieth century (Ward, 2015). Research found that the gender of individual's sexual interest can shift over their lifespan or in certain contexts (Baumeister, 2000; Blumstein \& Schwartz, 1977; Diamond, 2003, 2008; Goode \& Haber, 1997; Seidman et al., 1999; Sophie, 1986). LGB identities can develop in response to positive self-appraisals, appraisals from others, or in the context of same-sex romantic relationships (Kaufman \& Johnson, 2004). Some LGB individuals who self-label receive negative appraisals from others and may deemphasize that identity to avoid stigma, especially if they internalize those views (Kaufman \& Johnson, 2004; Taylor, 1999).

Along with biphobia, this "internalized heterosexism" may prevent some from taking on a LGB identity (Dworkin, 2001; Hutchins \& Kaahumanu, 1991; Ochs \& Deihl, 1992; Peterson \& Gerrity, 2006; Rowen \& Malcolm, 2002). Also called internalized homophobia, the internalization of negative societal attitudes toward homosexuality, or "heterosexism," by those with same-sex attractions is correlated with higher religiosity, substance use, sexual risk-taking, and poor mental and physical health (Amadio, 2006; Kashubeck-West \& Szymanski, 2008; Rowen \& Malcolm, 2002; Szymanski, Kashubeck-West, \& Meyer, 2008). Most prominent religious groups in the USA oppose same-sex relationships, and internalization of these views may explain why religious individuals who engage in same-sex behavior are more likely to identify as heterosexual (Szymanski et al., 2008). Additionally, the term "bisexual" often meets resistance and may be avoided due to disbelief of bisexuality as a legitimate sexual orientation (Israel \& Mohr, 2004; Rupp et al., 2013; Yost \& Thomas, 2012; Zivony \& Lobel, 2014). Many bisexual individuals wonder if they are "bisexual enough" to warrant the identity (Bower, Gurevich, \& Mathieson, 2002; Ochs, 2007), while some privately consider themselves bisexual, but avoid social conflict and rejection by allowing others to assume they are heterosexual (Ochs \& Deihl, 1992).

\section{Present Study Objectives}

We analyzed the Online College Social Life Survey (OCSLS), a dataset of over 24,000 students at 22 colleges and universities, to examine those who identified as heterosexual, but whose last hookup partner was same sex. Using only data on students whose last hookup partner was same sex, we analyzed whether a "heterosexual" identity correlated with demographics, attitudes, past sexual and relationship experience, and hookup encounter characteristics, and whether students comprised distinct groups. College experimentation scripts and theories related to performative bisexuality and fraternity hazing rituals suggest that same-sex encounters among students who identify as heterosexual may be more likely to take place among students with little prior same-sex experience, among fraternity and sorority members, those who are more accepting of or interested in sexual experimentation, involve only "low-level" sexual behavior, take place in public social settings, and involve intoxication. These students may be less likely than those with other identities to enjoy the encounter or want additional hookups or a relationship with their same-sex hookup partner. Our first research question asks: 
Research Question(R)1 Do characteristics of same-sex hookups among heterosexual college students align with college sexual scripting theory related to sexual experimentation, performative bisexuality, and/or fraternity hazing rituals?

The development stages model and the related social constructionist model predict that students with a heterosexual identity would have fewer same-sex sexual experiences and more other-sex sexual experiences shaping their identity. The development stages model also suggests those with a heterosexual identity may be younger, and especially attracted to and want a relationship with their partner (the "special case"). We next ask:

R2 Do these characteristics align with the developmental stages model and/or social construction model of identity theory?

Theory related to internalized heterosexism suggests heterosexually identified students may be more religious and socially conservative, have more negative sentiments about homosexuality, and take more risks, such as unprotected sex and binge drinking. We next ask:

R3 Do these characteristics students support an internalized heterosexism model?

We also explored racial patterns and how well students knew their partner to examine the degree to which Black men who have sex with anonymous male partners - the subject of much prior study - are prevalent in these data. We also explored whether some of these encounters were due to sexual assault. These research questions included:

R4 Are Black students and those who do not know their sexual partners well more prevalent among men who identify as heterosexual, but hookup with same-sex partners? And

R5 Were same-sex hookups among heterosexual students the result of sexual assault?

Prior theories may describe distinct groups that together comprise the students who identify as heterosexual but hookup with same-sex partners. Prior research tended to examine one group at a time, such as women who engage in public hookups with women, or those who exhibit internalized heterosexism, but has not addressed the prevalence of various groups or the extent to which the wider group of college students who hookup with same-sex partners can be described by these various and sometimes-competing theoretical frameworks. We draw upon latent class analysis methods to examine a final central research question:

R6 Are college students who hookup with same-sex partners, but identify as heterosexual comprised of distinct "types" that conform to various prevailing theories described in R1-R3, and what is the prevalence of each "type?"

\section{Method}

Subjects 
We analyzed the OCSLS, a survey of romantic and sexual partnering behavior collected between 2005 and 2011 from 24,131 students attending 22 colleges and universities. Questions asked about students' most recent dates and hookups, lifetime sexual behavior, and a variety of demographic and attitude questions. Professors of large introductory level courses and courses addressing sociology, family, sexuality, gender, and public health at these universities distributed surveys to students as a course assignment, offering an alternative assignment for students who did not participate. This sampling method resulted in a non-representative sample; elite research-oriented universities, underclasssmen, and women were overrepresented, and although almost $90 \%$ of participants were not sociology majors, around $80 \%$ of courses in which data were collected were sociology courses (Kuperberg \& Padgett, 2015). The response rate was over 99\% (Armstrong, England, \& Fogarty, 2009). The study was IRB approved at every college and university surveyed and at the university where data were analyzed.

\section{Measures}

The survey asked detailed information about student's characteristics and attitudes as well as the students' most recent hookup that occurred while they were in college, which is the data we focus on in this study. We examined variables related to students' social activities and attitudes, prior sexual and romantic history, characteristics of, and sentiments about student's last same-sex hookup. Several variables were collected using "strongly agree," "agree," "disagree," and "strongly disagree" as options; for simplicity sake, we dichotomize these measures into those who "agree" and "disagree," whether strongly or otherwise.

Several outcomes we examined had many missing responses. Attitude questions were not added to the survey until the fall of 2007, and we therefore had a smaller sample size for those questions than for other questions in the survey. Since this is a select small population, to make full use of the data we did not harmonize the data according to missing outcomes on outcome variables examined, and only deleted participants from the data based on missing responses related to key sexual identity, partner gender, and control variables. As a sensitivity test, we examined the likelihood of missing values on these variables for heterosexually identified students versus non-heterosexually identified students and found no significant differences in nonresponse with only two exceptions. (Full results are available from authors).

\section{Same-Sex Hookups and Sexual Orientation}

We identified same-sex hookups based on the reported gender of the participant and their most recent hookup partner. We labeled sexual identity using participants' response to the question, "What is your sexual orientation?" They chose from four possible responses: "homosexual," "heterosexual," "bisexual," and "I don't know." Regression analyses compared those "homosexual," "bisexual," or "I don't know" responses to "heterosexual" responses. We refer to the latter as "heterosexually-identified" and the former as "non-heterosexually-identified" for brevity; however, all such references refer only to students whose most recent hookup was with a same-sex partner.

While the overall measure capturing same-sex hookups did not include transgender partners, in terms of past experiences with partners we included some transgender partners; among non-heterosexually identified students, two women's last date partners were FTM transgender, and two men's last date partners were MTF transgender. We coded these as 
non-heterosexual dates. Similarly, three non-heterosexually-identified women reported that their last long-term relationship was with a FTM transgender person; we counted these as non-heterosexual relationships.

We identified 718 same-sex hookups, including 398 male-male hookups and 320 female-female hookups in this dataset using the self-reported gender of the participant, and the reported gender of their most recent hookup partner. However, approximately $7 \%$ (27 students) of male participants who reported a male partner in their last hookup also reported that they had vaginal sex during their last hookup or date. We cannot know if these participants mistakenly entered the wrong gender of their most recent hookup partner, mistakenly reported that they had vaginal sex during their last encounter, were using an alternative definition of vaginal sex or gender, were "jokesters" intentionally mis-answering questions, or were thinking of two different hookup partners when they answered these questions. Some may identify partners or themselves as "male" or "female" instead of identifying a partner or themselves as transgender, despite the availability of "transgender" as an option. Upon further investigation into other questions regarding all prior sexual experience, 14 students reported past sexual activity with a male partner; we retained these cases in the sample and removed the 13 who indicated they had vaginal sex with men but reported no sexual activity with men under their lifetime sexual behavior. We also removed 10 students (eight women and two men) missing information on race, religious attendance, and/or mother's education. Our final sample was the remaining 695 students whose most recent hookup was with a same-sex partner: 383 men and 312 women.

\section{Social Activities and Sexual Attitudes}

We examined several social activities and attitudes related to sexuality, homosexuality, and desires for hookups that may illuminate whether student's attitudes and characteristics align with theory related to sexual experimentation scripts, fraternity hazing rituals, and internalized heterosexism. We examined a measure of fraternity or sorority membership and agreement with the statements "Any kind of sexual activity is ok as long as both persons freely agree to it," "I wish there were more opportunities for hooking up at my college," and "I don't really want to be in an exclusive relationship now because I'd rather be free to date or hook up with multiple people." Social activities and attitudes related to internalized heterosexism and prior descriptions of this group included religious service attendance, divided into those who attended "never," "1-11 times per year," or "12 + times per year"; and agreement with the statement "My religious beliefs have shaped and guided my sexual behavior." Students were also asked, "What is your opinion about sexual relationships between two adults of the same sex?" and "There's been a lot of discussion about the way morals and attitudes about sex are changing in this country. If a man and a woman have sex relationship before marriage, do you think it is;" we examined a dichotomous measure of whether participants answered "always wrong" or "almost always wrong" versus "wrong only sometimes" or "not wrong at all" on these two questions. We also examined whether students characterized their political views as "liberal," "moderate" ("middle of the road"), or "conservative."

\section{Past Heterosexual and Same-Sex Sexual Experience}

Past same-sex relationship and sexual experience and past heterosexual sexual encounters may shape student's sexual identity, in alignment with developmental stages theory and theory related 
to the social construction of identity. Little prior same-sex experience may also indicate students are engaging in sexual experimentation. We first examined whether participant's last date and participant's last long-term relationship lasting longer than 6 months was with a non-heterosexual partner, examining only those who had been on a date or formed a relationship since starting college. We next examined lifetime measures of participants' experience with same-sex vaginal or anal sex (combining "vaginal sexual intercourse," "anal intercourse: you penetrated your partner" and "anal intercourse: your partner penetrated you"); same-sex oral sex (combining "you performed oral sex on your partner" and "your partner performed oral sex on you"); and hand-genital stimulation with a same-sex partner (combining "you stimulated your partner's genital with your hand" and "had your genitals stimulated by your partner's hand"). We also examined whether participants ever engaged in heterosexual vaginal sex.

\section{Characteristics of Most Recent Same-Sex Hookups}

We examined several variables related to characteristics of the same-sex hookup that students described in response to a series of questions headed by the statement "For this section, use whatever definition of hookup you and your friends generally use. It doesn't have to include sex to count if you and your friends would call it a hookup" and subheaded by the statement "Now, some questions about the last time you hooked up with someone you were NOT already in an exclusive relationship (whether or not you knew the person beforehand)." To examine the prevalence of anonymous hookups related to R4, we examined responses to "How well did you know the person you hooked up with before the day you two hooked up?" including the categories "very well," "moderately," "somewhat or a little bit," and "not at all." To examine characteristics associated with performative bisexuality narratives, we explored whether hookups included kissing or non-groping only (including "kissing" or "making out," "you touched your partner's breast or buttocks area," or "had your breast or buttocks touched by your partner," but no other sexual activity reported); whether hookups included any type of genital contact, including whether participants had oral sex, vaginal or anal sex, or handgenital stimulation (full definitions of these terms above); and a separate measure of whether hookups included vaginal or anal sex. We also examined whether hookups took place in public via responses to a question "when you hooked up, where did you go?" and whether students indicated "nowhere-we hooked up at a social event in plain sight" instead of one of the other options, which included "my room," "the other person's room," "in a private room somewhere else," or "other."

\section{Risk-Taking and Sexual Assault}

To examine characteristics associated with internalized heterosexism and the college experimentation/hookup script, both of which indicate a high rate of substance and sexual risk-taking during sexual encounters, we next examined risk-taking during same-sex hookups. We measured the number of drinks the participant had consumed before or during the hookup by totaling responses to questions about number of beers, glasses of wine, mixed drinks or shots, and malt beverages (Smirnoff ice, Bacardi breeze, Zima, etc.). In the latent class analysis, these were divided into those who did not drink, those who drank moderately or those who binge drank, measured as four or more drinks for women and five or more for men, using cutoffs from prior research on binge drinking in hookups (Kuperberg \& Padgett, 2017). Whether the participant used drugs was measured by the question "What drugs did you use before or during 
that occasion (check all that apply)?" A response of "yes" to any of the drugs (including marijuana, amphetamines (speed), cocaine, ecstasy (x, e), heroin, mushrooms, other) resulted in a 1 or a 0 for a response of "I did not take any drugs before or during the hookup." We measured whether male participants had anal sex during an encounter but answered no to the question "Did you use a condom?" with 1 indicating both of these were true and 0 indicating that they did not have anal sex during the encounter or used a condom if they did. Finally, we examined whether the hookup was the result of sexual assault (R5), by measuring whether the participant answered yes to any of three statements about activity during last hookup, including "Did you have sexual intercourse that was physically forced on you?"; "Did someone try to physically force you to have sexual intercourse, but you got out of the situation without having intercourse?"; and "Did someone have sexual intercourse with you that you did not want when you were drunk, passed out, asleep, drugged, or otherwise incapacitated?"

\section{Sentiments About Most Recent Same-Sex Hookup}

Sentiments about hookups after the fact can illuminate whether the hookup was a result of sexual curiosity now satisfied after experimentation or the beginning of some of the stages of identity development that may lead to future changes in identity. We examined responses to the question "looking back on this hookup, how do you feel about it?" focusing on the responses "I regret I did it" and "I'm glad I did it"; a third category "I'm neither glad nor regret it" was included in denominators, but not presented separately. We also examined average responses to "How much did you enjoy the hookup overall?" with responses ranging from $1=$ "not at all" to $4=$ "very much." Finally, we examined dichotomized responses to whether participants indicated some interest in response to "At the end of the hookup, were you interested in hooking up with this person again?" and "Were you interested in having a romantic relationship with the person you hooked up with after you hooked up?" with the responses "Yes, I was definitely interested," and "Maybe, it had some appeal" counted as a "1," and "Possibly, I didn't really know yet," and "No, I wasn't at all interested" counted as 0 .

\section{Demographic Variables}

We present results related to selection into a heterosexual identity among students whose last hookup was same-sex by demographic characteristics and later controlled for these characteristics in subsequent regression analyses. Related to development stages described in R2, age was examined in four groups: 18-19, 20-21, 22-23, and $24+$, although the Latent Class Analysis (discussed further below) examined only whether participants were 18 or an older age. Related to R4, race was examined in response to the question "If you had to pick one racial or ethnic group to describe yourself, which would it be?" with results separated into White, Black, Hispanic (including original categories Mexican-American and Other Hispanic), Asian [including original categories Chinese (from USA, PRC, Taiwan, Hong Kong, Singapore, etc.), Japanese, Korean, Filipino, Vietnamese, South Asian (Indian, Pakistani, etc.), Other Asian/Pacific Islander], and Other race (including original categories Native American Indian/Native Alaskan and Other). To account for past differences in hooking up and risk-taking found by past research (Kuperberg \& Padgett, 2015, 2016, 2017), we also examined and controlled for participant's mother's highest level of education by including a dichotomous measure of whether their mother had a bachelor's degree or graduate degree versus no college 
degree, and current cumulative GPA, including four dichotomous variables: $<2.1,2.1-3.0$, $3.1-3.75$, and $3.76+$.

Analytic Strategy

We estimated mixed-effects logistic and linear regression models comparing heterosexually-identified students whose last hookup was with a same-sex partner to those other-identified students on the basis of demographic characteristics, attitudes about sexuality, marriage, religion, past sexual and relationship experiences, and various characteristics of student's same-sex hookups. These types of models allowed us to account for clustering at the university level and were estimated using the meqrlogit and mixed commands in Stata. Results presented are regression-adjusted predicted means, produced using the predict command in Stata and then generating average predicted values by sexual orientation using tabstat. All models were estimated separately by gender, limited to students whose last hookup was with a same-sex partner, and controlled for age, race, mother's education, GPA, and religious service attendance. Finally, we used the doLCA command from the Latent Class Analysis (LCA) plugin in Stata (Lanza, Dziak, Huang, Wagner, \& Collins, 2015; LCA Stata Plugin, 2015) to conduct a LCA to determine whether certain characteristics correlated with underlying typologies defining distinct groups among heterosexually-identified students who engaged in same-sex hookups. LCA methods can illuminate latent typologies or "classes" and are preferable over more crude but analogous factor analysis or cluster analysis methods in offering analyses that are more in line with what is theoretically meaningful in social science research (Hagenaars \& Halman, 1989). Classes are assumed to be categorical, unlike factor analysis which assumes underlying "factors" are continuous (Collins \& Lanza, 2010). Results presented are the predicted probability that a participant was a member of a specific class; these are not interpreted similarly to factor loadings. Rather, values close to 1 or close to 0 indicate a strong relationship between a given variable and the latent class, but the distribution of probabilities across classes must also be examined to determine which variables are significant (Collins \& Lanza, 2010).

\section{Results}

Table 1 shows the self-identified sexual orientations or "sexual identity" of participants who engaged in same-sex hookups. Of the 383 male-male hookups examined, 12\% (or 45) were embarked on by a heterosexually-identified male participant, and among the 312 female-female hookups, $25 \%$ (or 77) were undertaken by a heterosexually-identified female participant. In the broader sample, same-sex hookups comprised $8.4 \%$ of the 4746 most recent hookup experiences reported by men, and 3.3\% of the last 9884 most recent hookup experiences reported by women. In general, women who hooked up with women had more variation in their sexual identities

compared to men who hooked up with men. Sixty-eight percent of men who hooked up with men identified as homosexual, versus only around $39 \%$ of women who hooked up with women. Around twice as many women as men identified as heterosexual (25\% of women vs. $12 \%$ of men) or bisexual ( $29 \%$ of women vs. $13 \%$ of men). Rates at which the participant was unsure of their sexuality were approximately equal, at around $7 \%$ for both men and women. 
Table 1 Self-identified sexual orientation of students whose last hookup was same sex

\begin{tabular}{llllll}
\hline & \multicolumn{2}{l}{ Men } & & \multicolumn{2}{l}{ Women } \\
\cline { 2 - 3 } \cline { 5 - 6 } & $N$ & $\%$ & & & $N$ \\
\hline Homosexual & 262 & 68.4 & & 122 & 39.1 \\
Bisexual & 51 & 13.3 & & 90 & 28.9 \\
I'm not sure & 25 & 6.5 & & 23 & 7.4 \\
Heterosexual & 45 & 11.8 & & 77 & 24.7 \\
Total $N$ & 383 & & 312 & \\
\hline
\end{tabular}

Characteristics of Students Who Hookup with Same-Sex Partners, by Sexual Identity

\section{Demographic Variables}

Table 2 presents odds ratios from mixed-effects models predicting a heterosexual identity among students' whose most recent hookup was with a same-sex partner, providing evidence of demographic selection into a heterosexual identity, with distinct patterns for men and women. Heterosexually-identified women were significantly younger, but men showed no significant difference by age in a heterosexual identity. Women had no significant difference in a heterosexual identity by race, but Asian men were less likely to identify as heterosexual than White men. Class impacted women's sexual identities, but not men's; women with a collegeeducated mother were significantly less likely to identify as heterosexual. GPA was not related to identity.

\section{Social Activities and Attitudes}

Religious, sexual, and political attitudes were correlated with sexual identity among students hooking up with same-sex partners. Table 2 demonstrates that religious service attendance was positively and significantly correlated with a heterosexual identity among both men and women. Table 3 presents significant differences in social activities and attitudes, with results presented being predicted percentages estimated from mixed-effects logistic regressions. Fraternity and sorority membership did not significantly differ by sexual identity nor did attitudes related to whether participants believed any consensual sex was ok, wanted more opportunities to hookup on campus, or wanted to avoid relationships so that they could date and hookup with multiple people. Four attitudes significantly differentiated heterosexually-identified men from nonheterosexually-identified men: Heterosexuals were more likely to agree that "religion informs my sexual decisions"; less likely to agree same-sex relationships were never wrong; more likely to agree that premarital sex was always wrong; and more likely to hold conservative political views. For female participants the same patterns held true, except that women additionally were more likely to identify as liberal if they had a non-heterosexual identity. 
Table 2 Mixed-effects logistic regressions predicting whether students who engaged in same-sex hookups identified as heterosexual (1) or homosexual, bisexual, or unsure (0)

\begin{tabular}{|c|c|c|c|c|}
\hline & \multicolumn{2}{|l|}{$\begin{array}{l}\text { Men } \\
(N=383)\end{array}$} & \multicolumn{2}{|l|}{$\begin{array}{l}\text { Women } \\
(N=312)\end{array}$} \\
\hline & Odds ratios & $\begin{array}{l}95 \% \text { Conf- } \\
\text { idence interval }\end{array}$ & Odds ratios & $\begin{array}{l}95 \% \\
\text { Confidence } \\
\text { interval }\end{array}$ \\
\hline \multicolumn{5}{|l|}{ Age 18-19 (ref) } \\
\hline Age $20-21$ & 1.44 & $0.63-3.31$ & 0.54 & $0.29-1.01$ \\
\hline Age $22-23$ & 1.42 & $0.51-3.93$ & $0.24 * *$ & $0.09-0.66$ \\
\hline Age $24+$ & 2.23 & $0.74-6.74$ & $0.25 *$ & $0.09-0.74$ \\
\hline \multicolumn{5}{|l|}{ White (ref) } \\
\hline Black & 0.25 & $0.05-1.32$ & 0.80 & $0.27-2.34$ \\
\hline Hispanic & 0.24 & $0.05-1.11$ & 1.33 & $0.57-3.11$ \\
\hline Asian & $0.12^{*}$ & $0.01-0.98$ & 1.78 & $0.67-4.70$ \\
\hline Other race & 0.67 & $0.12-3.80$ & 0.00 & $0.00-0.00$ \\
\hline Mother BA+ & 1.14 & $0.56-2.30$ & $0.51^{*}$ & $0.28-0.92$ \\
\hline GPA $<2.1$ & 2.33 & $0.27-18.44$ & 0.95 & $0.23-3.82$ \\
\hline GPA 2.1-3.0 & 4.39 & $0.88-21.98$ & 1.36 & $0.46-4.03$ \\
\hline GPA 3.1-3.75 & 3.40 & $0.72-16.09$ & 0.77 & $0.27-2.23$ \\
\hline \multicolumn{5}{|l|}{ GPA $3.75+$ (ref) } \\
\hline Attends religious services sometimes & $2.15^{*}$ & $1.05-4.41$ & $1.97 *$ & $1.07-3.63$ \\
\hline Attends religious services $1+/$ month & $4.62 *$ & $1.11-19.14$ & $3.22 *$ & $1.28-8.10$ \\
\hline
\end{tabular}

$* \mathrm{p}<.05 ; * * \mathrm{p}<.01 ; * * * \mathrm{p}<.001$

Past Non-heterosexual and Heterosexual Sexual Experience

All measures related to sexual and relationship experience presented in Table 3 were significantly related to students' sexual identity. Among both men and women whose last hookup partner was same-sex, those with a heterosexual identity were significantly less likely to report their last date or relationship was with a non-heterosexual partner, or that they had past 
experience of same-sex hand to genital stimulation, oral sex, and vaginal or anal sex. They were also significantly more likely to report past heterosexual vaginal sex.

\section{Characteristics of the Hookup and Later Sentiments}

Table 4 shows prior knowledge of partners, sexual activity, assault, and substance use during encounters, sentiments about the encounter, and differences by sexual identity among students whose last hookup was with a same-sex partner. Men with a heterosexual identity knew their same-sex partners significantly better than men with a non-heterosexual identity, but women had no significant differences in prior knowledge of partner. Almost a third of same-sex hookups among heterosexually-identified women took place in public, significantly more than among non-heterosexually-identified women, but this rate did not significantly differ among men. Both men and women with a heterosexual identity were significantly more likely to only engage in lower-order sexual activity during encounters and less likely to engage in genital contact, although there were no significant differences in prevalence of anal or vaginal sex, unprotected anal sex, or sexual assault.

In terms of other types of risk-taking, men who identified as heterosexual had consumed a significantly higher number of drinks before or during hookup, but women did not, and no significant differences in drug use occurred by sexual identity. There were no significant differences among men and women by sexual identity in terms of regret about the hookup, but both men and women with a heterosexual identity were significantly less likely than those with another identity to be glad about the hookup or to describe it as enjoyable, and women with a heterosexual identity were also significantly less likely to be interested in a repeat hookup or a relationship with the same-sex partner from their last hookup.

Table 3. Characteristics of students who hookup with same-sex partners, by gender and sexual identity (regression-adjusted means predicted from mixed effects logistic regressions)

\begin{tabular}{|c|c|c|c|c|c|c|c|c|}
\hline & \multicolumn{4}{|l|}{ Men } & \multicolumn{4}{|l|}{ Women } \\
\hline & $\begin{array}{l}\text { Homosexual/ } \\
\text { bisexual/ } \\
\text { unsure }\end{array}$ & $N$ & Heterosexual & $N$ & $\begin{array}{l}\text { Homosexual/ } \\
\text { bisexual/ } \\
\text { unsure }\end{array}$ & $N$ & Heterosexual & $N$ \\
\hline Sorority or fraternity member & 7.7 & 337 & 17.8 & 44 & 4.1 & 235 & 4.2 & 77 \\
\hline Agrees any consensual sex ok & 91.1 & 335 & 91.7 & 44 & 89.2 & 235 & 95.2 & 74 \\
\hline $\begin{array}{l}\text { Wants more opportunities to } \\
\text { hook up on campus }\end{array}$ & 51.4 & 333 & 43.1 & 43 & 28.3 & 233 & 29.0 & 74 \\
\hline $\begin{array}{l}\text { Doesn't want to be in an } \\
\text { exclusive relationship so can } \\
\text { date/hookup with multiple } \\
\text { people }\end{array}$ & 34.3 & 332 & 40.5 & 44 & 27.1 & 235 & 35.5 & 75 \\
\hline $\begin{array}{l}\text { Agrees religion shapes my } \\
\text { sexual decisions }\end{array}$ & $16.3^{*}$ & 334 & 34.1 & 44 & $16.4^{*}$ & 235 & 31.4 & 75 \\
\hline $\begin{array}{l}\text { Agrees Same-sex sexual } \\
\text { relations are not wrong }\end{array}$ & $97.8 * * *$ & 304 & 73.3 & 43 & $97.2 * *$ & 220 & 85.4 & 68 \\
\hline
\end{tabular}




\begin{tabular}{lllllllll}
\hline Agrees premarital sex is wrong & $2.0^{* *}$ & 302 & 14.7 & 42 & $2.9^{*}$ & 214 & 8.5 & 65 \\
Liberal political views & 77.0 & 311 & 58.6 & 43 & $88.2^{* *}$ & 225 & 66.3 & 71 \\
$\begin{array}{l}\text { Conservative political views } \\
\text { 2.9** }\end{array}$ & 311 & 24.1 & 43 & $1.6^{*}$ & 225 & 9.4 & 71 \\
$\begin{array}{l}\text { Last date was with } \\
\text { non-heterosexual partner (if } \\
\text { dated) }\end{array}$ & $91.3^{* * *}$ & 265 & 54.6 & 34 & $80.6^{* * *}$ & 187 & 16.3 & 59 \\
$\begin{array}{l}\text { Last long-term relationship was } \\
\text { with non-heterosexual partner (if } \\
\text { long-term relationship) }\end{array}$ & $90.1^{*}$ & 102 & 69.9 & 24 & $68.8^{* * *}$ & 141 & 12.5 & 32 \\
$\begin{array}{l}\text { Past experience same-sex hand } \\
\text { to gential stimulation }\end{array}$ & $98.7^{* * *}$ & 338 & 51.5 & 45 & $93.1 * * *$ & 235 & 22.7 & 45 \\
$\begin{array}{l}\text { Past experience same-sex oral } \\
\text { sex }\end{array}$ & $97.6^{* * *}$ & 338 & 54.0 & 45 & $82.0^{* * *}$ & 235 & 21.9 & 45 \\
$\begin{array}{l}\text { Past experience same-sex } \\
\text { vaginal or anal sex }\end{array}$ & $80.3^{* * *}$ & 338 & 17.3 & 45 & $43.1 * * *$ & 235 & 4.1 & 77 \\
\begin{tabular}{l} 
Past heterosexual vaginal sex \\
\hline
\end{tabular} & $21.8^{*}$ & 338 & 33.7 & 45 & $57.3^{* *}$ & 235 & 75.4 & 77 \\
\hline
\end{tabular}

Regression adjusted to standardize for age (Ref: 18-19), race (Ref: White), religious attendance (Ref: Never), GPA (Ref: $3.75+$ ) and mother has

a college degree (Ref: Does not)

$* \mathrm{p}<.05 ; * * \mathrm{p}<.01 ; * * * \mathrm{p}<.001$

Table 4 Characteristics of last same-sex hookup partner and last same-sex hookup, by gender and sexual identity (regression-adjusted means predicted from mixed-effects logistic regression)

\begin{tabular}{|c|c|c|c|c|c|c|c|c|}
\hline & \multicolumn{4}{|l|}{ Men } & \multicolumn{4}{|l|}{ Women } \\
\hline & $\begin{array}{l}\text { Homosexual/ } \\
\text { bisexual/ } \\
\text { unsure }\end{array}$ & $\mathrm{N}$ & Heterosexual & $\mathrm{N}$ & $\begin{array}{l}\text { Homosexual// } \\
\text { bisexual/ } \\
\text { unsure }\end{array}$ & $\mathrm{N}$ & Heterosexual & $\mathrm{N}$ \\
\hline Knew partner & & 338 & & 45 & & 235 & & 77 \\
\hline Very well & 12.2 & & 17.6 & & 33.0 & & 36.8 & \\
\hline Moderately well & $13.1 * *$ & & 32.0 & & 29.3 & & 18.8 & \\
\hline Somewhat or a little bit & 45.5 & & 40.7 & & 29.4 & & 33.6 & \\
\hline Not at all & $29.5^{*}$ & & 10.9 & & 8.5 & & 10.7 & \\
\hline Hookup took place in public & 5.9 & 336 & 9.7 & 45 & $11.2 * * *$ & 233 & 29.4 & 76 \\
\hline $\begin{array}{l}\text { Hookup included kissing or } \\
\text { above-the-waist groping only }\end{array}$ & $6.7 * * *$ & 336 & 29.0 & 42 & $28.1 * *$ & 232 & 49.2 & 76 \\
\hline Hookup included any genital contact & $93.3 * * *$ & 338 & 71.0 & 45 & $71.9 * *$ & 235 & 50.8 & 77 \\
\hline
\end{tabular}




\begin{tabular}{lllllllll}
\hline $\begin{array}{l}\text { Hookup included vaginal or anal } \\
\text { sex }\end{array}$ & 37.7 & 338 & 24.7 & 45 & 17.4 & 235 & 26.0 & 77 \\
$\begin{array}{l}\text { Hookup included anal sex } \\
\text { without a condom }\end{array}$ & 6.4 & 338 & 10.5 & 45 & - & - & - & - \\
$\begin{array}{l}\text { Rape (forced, incapacitated or } \\
\text { attempted) }\end{array}$ & 5.7 & 337 & 12.1 & 42 & 2.3 & 234 & 3.4 & 75 \\
$\begin{array}{l}\text { \# Of drinks before or during } \\
\text { hookup }\end{array}$ & $2.4^{* *}$ & 338 & 4.3 & 45 & 3.0 & 235 & 3.9 & 77 \\
$\begin{array}{l}\text { Used drugs during or before } \\
\text { hookup }\end{array}$ & 15.6 & 338 & 18.0 & 45 & 11.4 & 235 & 6.9 & 77 \\
$\begin{array}{l}\text { Regrets hookup } \\
\text { Glad about hookup }\end{array}$ & 13.8 & 260 & 13.3 & 35 & 9.8 & 172 & 13.8 & 63 \\
$\begin{array}{l}\text { How much Enjoyed Hookup } \\
\text { overall (1=not at all, 4=very } \\
\text { much) }\end{array}$ & $2.1 *$ & 317 & 1.9 & 40 & $2.5^{* *}$ & 226 & 2.2 & 69 \\
$\begin{array}{l}\text { Interested in hooking up again } \\
\text { Interested in relationship with }\end{array}$ & 54.2 & 239 & 43.4 & 39 & $74.1^{* * *}$ & 216 & 46.9 & 68 \\
\hline hookup partner
\end{tabular}

Regression adjusted to standardize for age (Ref: 18-19), race (Ref: White), religious attendance (Ref: Never), GPA (Ref: $3.75+$ ) and mother has a college degree (Ref: Does not) ${ }^{*} \mathrm{p}<.05$; $* * \mathrm{p}<.01 ; * * * \mathrm{p}<.001$

\section{Latent Class Analysis}

To investigate whether heterosexually-identifed students who hookup with same-sex partners can be described as comprising distinct types, we conducted a latent class analysis of these students $(\mathrm{N}=122)$ using several of the variables described above. This analysis did not include nonheterosexually-identifed students. We selected variables for the latent class analysis based on several criteria: first, several variables aligned with theoretical explanations for heterosexually-identifed students hooking up with samesex partners. Second, we selected variables that the above analyses indicated were unusually common among heterosexual-identifying students who hooked up with same-sex students, compared to non-heterosexually-identifed students who hooked up with same-sex students.

Table 5 shows $\mathrm{ft}$ statistics for the models with diferent number of classes of heterosexuals who hooked up with same-sex partners. AIC and adjusted BIC values gave support for a 6-class solution; we gave greater weight to adjusted BIC as recommended by Tein, Coxe, and Cham (2013). Table 6 shows the variable correlations with each class. Numbers represent the probability of certain characteristics occurring among members of that "class"; probabilities close to 0 or 1, or unusually high for that variable, are especially of note (Collins \& Lanza, 2010) and we bold probabilities that are unusually high. Rape or attempted rape during a hookup and fraternity/sorority membership was not strongly correlated with any of the classes.

The frst three classes, which we describe as "Experimentation/Early Stages," shared the fact that they were mostly private encounters that took place among those who agreed premarital sex, consensual sex, and homosexuality were not almost always or always wrong, were not 
particularly religious, and whose actions may be said to conform with a sexual experimentation script, or may suggest earlier stages of non-heterosexual identity development. Comprising 29\% of heterosexually-identifed students who hooked up with same-sex partners, the frst and largest class, which we refer to as "wanting more," were those who very much enjoyed the encounter, had the second highest rate of wanting a later relationship with the partner $(57 \%)$, and were the most likely to have engaged in prior same-sex penetrative vaginal or anal sex; although only $30 \%$ had previously engaged in this activity; this was the highest correlation for any class. A total of $68 \%$ had some kind of genital contact with their partner during the encounter. $42 \%$ had been binge drinking but nearly half did not drink during the encounter; the second highest rate for any class.

The second largest group, comprising $22 \%$ of participants, whom we describe as "drunk and curious," consisted of those with little prior homosexual sexual experience (5\%) and who were especially likely to be binge drinking during the encounter $(72 \%)$. They had the highest rate of describing themselves as politically liberal among the frst three classes, and the second highest overall, and were strong supporters of premarital sex and consensual sex generally, with $96 \%$ agreeing both were ok, although $38 \%$ admitted to religious infuence on their sexuality, and $20 \%$ thought homosexuality was almost always or always wrong. While this group had the highest rates of engaging in genital contact at $80 \%$, unlike the frst class, they mostly did not want a future relationship with their last same-sex hookup partner, with only $4 \%$ wanting such an encounter, and most commonly said they enjoyed the hookup "somewhat" (57\%), while 23\% enjoyed it "not at all" and none said they enjoyed it "very much." By contrast, in the first group, over half enjoyed the hookup "very much" and almost all the remainder enjoyed it "somewhat." This group was most likely to know their partner "not at all" before that night (34\%).

The third group, which we describe as "little enjoyment," was least likely to report enjoying the encounter with $81 \%$ stating they enjoyed it "very little" and almost none wanting a future relationship. This group was most likely to describe themselves as politically middle of the road, to have been drinking moderately, and had the least overall support for any consensual sex being ok of any class, although $76 \%$ still agreed it was ok, and all were in support of premarital sex. Like the second class, some said religion infuenced their sexual decisions, and not all agreed homosexual relationships were always ok. Apart from their low level of enjoyment and level of inebriation, what distinguished this class from the first two was their low level of sexual activity; $82 \%$ did not proceed beyond kissing and groping during the encounter. All knew their partners moderately or very well before they hooked up with them. Comprising $9 \%$ of heterosexually-identifed participants who hooked up with same-sex partners, this was one of the smaller classes.

Comprising $21 \%$ of heterosexually-identifed participants who hooked up with same-sex partners, the fourth class, whom we refer to as "maybe for show," conformed closely to theory regarding performative bisexuality. All participants in this class were women, $70 \%$ were age 18 , and $98 \%$ of these encounters took place in public "at a social event in plain sight." Students in this class were also most likely to be binge drinking (84\%), did not have any prior experience with same-sex vaginal sex $(0 \%)$, mostly only kissed or groped breasts or buttocks during the encounter $(91 \%)$, and only a minority were interested in a future relationship with their hookup afterward (9\%) although 31\% enjoyed the encounter "very much." Students in this class universally described themselves as politically liberal, and agreed premarital sex, any consensual sex, and homosexual relations were ok. They were the least religious of any class, with $82 \%$ never attending religious services, and only $8 \%$ stating religion informed their sexual decisions. 
Table 5 Model fit statistics for the optimal number of classes of heterosexuals hookind up with same-sex partners

\begin{tabular}{|l|l|l|l|l|l|}
\hline $\begin{array}{l}\text { Number of } \\
\text { classes }\end{array}$ & Log-likelihood & AIC & BIC & Adjusted BIC & Entropy R-Sqd \\
\hline 1 & -1328.99 & 1549.28 & 1616.58 & 1540.69 & NA \\
\hline 2 & -1288.44 & 1518.19 & 1655.59 & 1500.66 & .77 \\
\hline 3 & -1240.24 & 1471.78 & 1679.28 & 1445.31 & .80 \\
\hline 4 & -1207.33 & 1455.97 & 1733.57 & 1420.56 & .90 \\
\hline 5 & -1185.14 & 1461.59 & 1809.29 & 1417.23 & .90 \\
\hline 6 & $\mathbf{- 1 1 5 7 . 7 9}$ & $\mathbf{1 4 5 6 . 8 8}$ & $\mathbf{1 8 7 4 . 6 8}$ & $\mathbf{1 4 0 3 . 5 7}$ & $\mathbf{. 9 1}$ \\
\hline 7 & -1140.92 & 1473.15 & 1961.05 & 1410.90 & .93 \\
\hline 8 & -1123.62 & 1488.56 & 2046.56 & 1417.36 & .93 \\
\hline
\end{tabular}

Bold values are unusually high proportions

The last two classes comprised those who were religious, and whose religious identity perhaps conflicted with a nonheterosexual identity. The fifth group we term "loved it, but religious." This group consisted of mostly women (92\%), who especially enjoyed their encounter compared to other classes, but with $45 \%$ attending services at least once a month and the remaining 55\% attending at least once a year but less than once a month, they were also the most likely to attend religious services regularly. Further, 57\% stated that religion informed their sexual views. Regarding sexuality, their views were more mixed: A signifcant minority thought homosexuality (33\%) and premarital sex (27\%) was almost always or always wrong, but $92 \%$ also stated any consensual sex was ok. About two-thirds of this class were age $18(65 \%)$. This class distinguished itself by being most interested in a relationship after a hookup (71\%), and the most likely to state they enjoyed the hookup very much (78\%), while also the most likely to have not been drinking during the hookup (51\%). This group shared much in common with the frst class, but was distinguished from the frst class by their younger age, less prior same-sex sexual experience $(0 \%)$, and higher rate of religiosity.

The final and smallest class $(7 \%)$, which we refer to "just not who I can be," comprised those whose characteristics corresponded with theory related to internalized heterosexism. Almost all men (98\%), this class was not likely to attend religious services at least monthly like the prior class, but 98\% attended services between 1 and 11 times in the past year, and they had the highest rate of stating religion informed their sexual views (87\%). This group was also almost universally likely to state homosexual relations were almost always or always wrong (98\%), and $70 \%$ of this group thought premarital sex was almost always or always wrong. This group was most likely to describe themselves as politically conservative (43\%). Although only some wanted a relationship with their same-sex partner after the hookup (13\%), this group 
mostly enjoyed the hookups somewhat or very little, distinguishing themselves from the ffth class who were more likely to say they enjoyed it very much.

Table 6. Latent class analysis: Heterosexual students who hookup with same-sex partners

\begin{tabular}{|c|c|c|c|c|c|c|}
\hline & \multicolumn{3}{|c|}{ Experimentation/early states } & \multirow{2}{*}{$\begin{array}{l}\text { College scripts } \\
\text { Maybe for } \\
\text { show }\end{array}$} & \multicolumn{2}{|l|}{ Religious } \\
\hline & $\begin{array}{l}\text { Wanting } \\
\text { more }\end{array}$ & $\begin{array}{l}\text { Drunk and } \\
\text { curious }\end{array}$ & $\begin{array}{l}\text { Little } \\
\text { enjoyment }\end{array}$ & & $\begin{array}{l}\text { Loved it, but } \\
\text { religious }\end{array}$ & $\begin{array}{l}\text { Just not } \\
\text { who I can } \\
\text { be }\end{array}$ \\
\hline Female & 0.36 & 0.75 & 0.49 & 1.00 & 0.92 & 0.02 \\
\hline Age 18 & 0.35 & 0.20 & 0.26 & 0.70 & 0.65 & 0.25 \\
\hline Fraternity or sorority member & 0.22 & 0.05 & 0.00 & 0.00 & 0.00 & 0.14 \\
\hline Religious services: never & 0.29 & 0.48 & 0.33 & 0.82 & 0.00 & 0.01 \\
\hline Religious services $1-11 \times /$ year & 0.65 & 0.44 & 0.66 & 0.11 & 0.55 & 0.98 \\
\hline Religious services $1+/$ month & 0.06 & 0.08 & 0.00 & 0.07 & 0.45 & 0.01 \\
\hline Religion informs sexual views & 0.06 & 0.38 & 0.42 & 0.08 & 0.57 & 0.87 \\
\hline Premarital sex wrong & 0.00 & 0.04 & 0.00 & 0.00 & 0.27 & 0.70 \\
\hline Homosexual relations wrong & 0.00 & 0.20 & 0.17 & 0.00 & 0.33 & 0.98 \\
\hline Any consensual sex is $\mathrm{OK}$ & 1.00 & 0.96 & 0.76 & 1.00 & 0.92 & 0.88 \\
\hline Politically liberal & 0.67 & 0.84 & 0.39 & 1.00 & 0.35 & 0.42 \\
\hline Politically moderate & 0.18 & 0.00 & 0.61 & 0.00 & 0.44 & 0.15 \\
\hline Politically conservative & 0.14 & 0.16 & 0.00 & 0.00 & 0.21 & 0.43 \\
\hline At end of hookup interested in relationship & 0.57 & 0.04 & 0.01 & 0.09 & 0.71 & 0.13 \\
\hline \multicolumn{7}{|l|}{ How much enjoyed hookup overall } \\
\hline None & 0.05 & 0.23 & 0.00 & 0.07 & 0.00 & 0.14 \\
\hline Very little & 0.00 & 0.20 & 0.81 & 0.14 & 0.00 & 0.41 \\
\hline Somewhat & 0.44 & 0.57 & 0.18 & 0.48 & 0.22 & 0.44 \\
\hline Very much & 0.51 & 0.00 & 0.01 & 0.31 & 0.78 & 0.01 \\
\hline Did not drink & 0.49 & 0.16 & 0.27 & 0.07 & 0.51 & 0.25 \\
\hline
\end{tabular}




\begin{tabular}{|c|c|c|c|c|c|c|}
\hline Moderate drinking & 0.09 & 0.13 & 0.72 & 0.09 & 0.07 & 0.25 \\
\hline Binge drinking & 0.42 & 0.72 & 0.01 & 0.84 & 0.42 & 0.50 \\
\hline Rape or attempted rape during hookup & 0.08 & 0.16 & 0.00 & 0.00 & 0.00 & 0.16 \\
\hline Prior experience same-sex vaginal/anal sex & 0.30 & 0.05 & 0.00 & 0.00 & 0.00 & 0.00 \\
\hline Only kissed or groped breasts or buttocks & 0.32 & 0.20 & 0.82 & 0.91 & 0.35 & 0.43 \\
\hline Took place "at a social event in plain sight" & 0.00 & 0.01 & 0.26 & 0.98 & 0.33 & 0.24 \\
\hline \multicolumn{7}{|l|}{ Knew partner before hookup } \\
\hline Not at all & 0.00 & 0.34 & 0.00 & 0.20 & 0.00 & 0.25 \\
\hline Somewhat or a little bit & 0.10 & 0.25 & 0.00 & 0.14 & 0.16 & 0.48 \\
\hline Moderately & 0.67 & 0.15 & 0.83 & 0.29 & 0.39 & 0.26 \\
\hline Very well & 0.23 & 0.26 & 0.17 & 0.36 & 0.45 & 0.01 \\
\hline Proportion in class & 0.29 & 0.22 & 0.09 & 0.12 & 0.21 & 0.07 \\
\hline
\end{tabular}

Bold values are unusually high proportions

\section{Discussion}

This study was the first to conduct a systematic comparison and analyses of heterosexually-identified students who hook up with same-sex partners, and the specific circumstances under which those hookups occur. The large, rich dataset we draw upon is superior to other samples that relied on snowball sampling or recruitment through specific LGB venues, because the size allowed for us to examine rare groups, including heterosexuallyidentified students who hookup with same-sex partners, and features of those encounters. However, it was not without limitations. The dataset is not representative of college students in general. Within colleges, the inclusion of some courses addressing gender and sexuality in the sample likely led to greater selection among students who were questioning their sexual orientation or generally more interested in sexual topics than other students, leading to some skewing of results, especially overall rates at which sexual identities may occur. The survey only included college students, and only asked about one hookup they experienced, and cannot tell us about same-sex hookups among self-identified heterosexuals who are not in college, or the trajectory of sexual identity formation. Finally, the large number of tests we conducted may have increased Type-1 errors (false positives) while the small sample may have increased Type-2 errors (false negatives).

Heterosexually-identified students who hookup with same-sex partners comprised a substantial number of samesex hookups. In these data, heterosexually-identified students accounted for approximately one in nine participants of the most recent same-sex hookups among college men, and one in four of the most recent same-sex hookups among college women. Findings suggest that survey questions designed to capture sexual orientation data may 
be instead measuring sexual identity. Unlike sexual orientation, which describes sexual feelings toward one or more genders and may be biologically based, sexual identity is adopted by individuals within a specific sociohistorical context, precluding some with same-sex attractions from taking on such an identity. Same-sex sexual behavior may also be undertaken by those who may not have an attraction to same-sex partners in specific sociohistorical contexts where sexual "scripts" encourage same-sex sexual contact and sexual experimentation (Simon \& Gagnon, 1986, 2003). The script of women engaging in same-sex low-level hookups at public parties in college is one such social script (Sanday, 2007).

\section{Sexual Experimentation Scripts}

Our first research question asked whether findings aligned with a sexual experimentation script, which could include performative bisexuality or fraternity hazing rituals. We found little support for fraternity hazing rituals being a factor; heterosexually identified students were not more likely to be in fraternities or sororities. Students may not conceptualize these encounters as "hookups." However, many findings supported a sexual experimentation/partying narrative. For instance, heterosexually-identified men drank more during encounters. Heterosexually-identified students reported enjoying encounters less but were not more likely to report regretting the experience, perhaps indicating some experimental nature of many of these encounters; students did not regret experimenting, but some found that they did not enjoy that experiment, reaffirming a heterosexual identity. Heterosexually-identified women were less likely to be interested in a repeat performance or future relationship with their last same-sex hookup partner, also supporting an experimentation narrative. Some findings challenged a sexual experimentation narrative, as sexual identity did not correlate with belief in the acceptability of any consensual sex, wanting more hookup opportunities or wanting to avoid exclusive relationships to hookup with multiple people. Performative bisexuality explanations were also supported by our findings; heterosexually identified women were more likely to hookup with same-sex partners in a public space, consistent with prior descriptions.

\section{Sexual Identity Development and Internalized Heterosexism}

Our second research question asked whether student's characteristics aligned with sexual identity theory, either that related to sexual identity development, or the social constructionist model. When compared with those other-identified students, heterosexually-identified women engaging in same-sex hookups tended to be younger and were less likely to have had prior nonheterosexual sexual, dating, or relationship experience, while more likely to have had heterosexual vaginal sex. These findings support both theories related to sexual identity development, and the social construction of sexuality, which indicate sexual identity is developed and reaffirmed via experiences with samesex and other-sex partners.

Our third research question focused on internalized heterosexism. Internalized heterosexism was reflected in the lower acceptance of same-sex sexual relations among those with a heterosexual identity and, in line with literature on heterosexism, religious service attendance and religious influence on sexual behavior also correlated with a heterosexual identity for both men and women, as did conservative political and sexual views. In contrast to theory on internalized heterosexism and risk-taking, heterosexual students were not more likely to have unprotected sex or use drugs during encounters, but men (who we found in the latent class 
analysis comprised almost all of those who could be described as experiencing internalized heterosexism) drank more alcohol.

Race and Knowledge of Partners, Sexual Assault

Our data also allowed us to systematically examine racial differences in the same-sex hookups of heterosexually-identified college men and how well they knew their partner. Our fourth research question centered on whether race and knowledge of partners aligns with research of men who have sex with men anonymously on the "down low." In contrast with a media and academic research focus on African-American men who have sex with men (Ward, 2015), we found that White men are significantly more likely than Asian men and no different than Black men to report a "heterosexual" identity despite engaging in same-sex hookups. Other findings also call into question the sample selection methods of researchers seeking to examine men on "the down low"; heterosexually-identified men knew their partners better than those with other identities, indicating these were not necessarily the random hookups described in past studies that relied on, for instance, samples of men who hooked up with men in public places. Research has found that students who knew their partners better tended to take more risks such as unprotected sex (Kuperberg \& Padgett, 2017), indicating the importance of studying encounters among heterosexually identified men who have sex with men they know well, which may not be captured via more commonly used methods of recruitment that focus on anonymous hookups. Our fifth research question also asked whether these encounters were a result of sexual assault, but we do not find support for a higher rate of sexual assault among those with a heterosexual identity.

Who Comprises Heterosexual Students Who Hookup with Same-Sex Partners?

Our final research question asked whether students who reported hooking up with same-sex partners, but identified as heterosexual, could be divided into certain "types" described by the above theories, and we found through latent class analyses that they comprised six groups. The first three were those that can be classified as various types of mostly private experimentation, which may be correlated with engaging in a college experimentation script, and/or the early stages of identity development and experiences that can lead to a later identity change.

Comprising $60 \%$ of same-sex hookups among heterosexuals, these hookups did not take place in public for the most part and took place among students with positive views of premarital sex and homosexuality. The three classes differed on the basis of students' later sentiments about the encounter, desire for a relationship with that partner, prior homosexual experience, and drinking during the encounter. While the first class ("wanting more") wanted relationships with their partners and may later change their identity, the second class ("drunk and curious") seems to have experimented perhaps for the sake of sexual experimentation, and while they enjoyed their experiment, did not desire a relationship with their hookup. In the future, they may retain a heterosexual identity or change it in reaction to a same-sex hookup or relationship they feel more strongly about pursuing beyond a sexual encounter. These first two classes may be akin to Cass' (1996) "special case" pathway for those identifying as heterosexual in early stages of identity development, where students view themselves as heterosexual apart from this one partner or single event but may later form a relationship that leads to adoption of an LGB sexual identity. The third class ("little enjoyment") consisted of those who experimented and perhaps confirmed 
a heterosexual identity after not enjoying the encounter and ended the encounter before proceeding to higher order sexual activity. This class may chalk this up as an experience to check off their college experimentation list and retain a heterosexual identity, or instead may later engage in more enjoyable samesex encounters that lead to a shift in identity.

The fourth class ("maybe for show") was women, often 18, who kissed and "made out" with same-sex partners in public settings. These students may be engaging in performative hookups (Hamilton, 2007) in accordance with performative bisexuality social scripts aimed at attracting men, but may also be using these opportunities to experiment with same-sex attraction (Ward, 2015); about one in 10 stated they wanted a future relationship with the partner, and a third enjoyed the encounter "very much." Finally, the last two classes were religious students whose strong religious participation or influence on their behavior likely affected sexual identity. Comprising over one-fourth of students who identified as heterosexual, the majority ("loved it, but religious") did not conform to theory related to internalized heterosexism, but instead may have been conflicted about taking on a nonheterosexual identity given their frequent religious attendance. They were also especially young and inexperienced in same-sex relationships and had a high level of enjoying the encounter; this group also conforms to theory on sexual identity development and may take on a non-heterosexual identity later in life, but may delay that stage compared to less religious students due to their religious engagement. The final class ("just not who I can be"), the smallest class, which was almost all male, were those who had strong views against homosexuality, which has been termed "internalized heterosexism."

Past theory on sexual scripts, identity development theory (whether via stages or socially constructed), and internalized heterosexism all contribute to the patterns we find but describes distinct groups who together comprise those who identify as heterosexual but hookup with same-sex partners. Past research has usually been qualitative and generally focused on only one of these groups and/or theory of a heterosexual identity among those who engage in same-sex behavior, such as women hooking up with women at fraternity parties (Hamilton, 2007). Our data allowed a more comprehensive quantitative analysis which permitted us to reveal the degree to which these somewhat different theories may describe college students accurately, and the prevalence of certain "types" among students.

Implications

The degree to which students and individuals choose to adopt a non-heterosexual identity varies by social context and the circumstances of the encounter, with college being a context particularly fraught with specific sexual scripts institutionalized into the fabric of social life (Ward, 2015). We found most students who engaged in same-sex hookups but identified as heterosexual could be described as privately experimenting and/or having religious conflicts with assuming an LGB identity. Some of these students may later change their sexual identity, but others will retain a heterosexual identity. Theory related to performative bisexuality and internalized heterosexism described only a minority of these students (12 and 7\%, respectively), while research on Black men on the "down low" and men having anonymous hookups with men exclude most same-sex hookups between those who identify as heterosexual. Research limited to those self-identifying as LGB will also miss a significant minority of those who engage in same-sex sexual encounters. Findings also suggest that not everybody who engages in same-sex behavior is "secretly gay," but rather may be engaging in socially scripted sexual experimentation that will not have long-term implications for their identity, while others may 
retain a heterosexual identity (rather than a LGB identity) to resolve conflicts between their religious beliefs and community standards, and samesex sexual desires and actions. For a minority, a heterosexual identity seems related to internalized heterosexism, and for men, incongruence in identity and behavior is also associated with higher alcohol use during same-sex encounters. These findings have clinical implications for those experiencing distress regarding same-sex hookups and/or sexual identity. In recent years as LGB identities have become more socially acceptable, the types of people selecting into a nonheterosexual identity may have changed, as these identities have been publicly adopted by a wider swath of the population (Baunach, 2012; Laughlin, 2016). This dataset was collected during a certain historical-time period (2005-2011), during which gay rights activity was both energized and the subject of polarizing debate as gay marriage was being adopted by more and more states, but not yet legal nationwide. A research report collected after the legalization of gay marriage nationwide (2016) found that among a random sample of young adults aged 13-20, who have grown up in a world where legal gay unions have been available in some U.S. states for as long as they can remember (civil unions became legal in Vermont in 2000; same-sex marriage in Massachusetts in 2004), only $48 \%$ identify as "completely heterosexual," down from $65 \%$ among those aged $21-34$ (Laughlin, 2016). As young adults come of age in a new social system where gay marriage is legal, and as progress continues to be made in anti-discrimination legislation, patterns related to sexual identity will likely continue to shift and should be the subject of continuing research among college students and in other settings and populations. We suggest longitudinal studies to examine the evolution of sexual identity, meaning-making, and heterosexually identified adults engaging in same-sex hookups. Acknowledgements The authors thank Joseph Padgett, R. James Leister, Lonnie McLendon, Rachel Madsen, and Stephanie Pruitt for their research assistance on this project, as well as Sara Crawley and Joseph Padgett for their helpful advice. This project was funded by a University of North Carolina at Greensboro New Faculty Research Grant and a New Faculty Summer Excellence Award Grant, as administered by the Office of Sponsored Programs. An earlier version of this paper was presented at the Southern Sociological Society Conference, Charlotte, NC, 2014.

\section{References}

Amadio, D. M. (2006). Internalized heterosexism, alcohol use, and alcohol-related problems among lesbians and gay men. Addictive Behaviors, 31, 1153-1162.

Armstrong, E. A., England, P., \& Fogarty, A. C. K. (2009). Orgasm in college hook ups and relationships. In B. Risman (Ed.), Families as they really are (pp. 362-377). New York: Norton.

Baumeister, R. F. (2000). Gender differences in erotic plasticity: The female sex drive as socially flexible and responsive. Psychological Bulletin, 126, 347-374.

Baunach, D. M. (2012). Changing same-sex marriage attitudes in America from 1988 through 2010. Public Opinion Quarterly, 76, 364-378.

Bleich, S., \& Taylor-Clark, K. (2005). Black men on the "down-low" and the HIV epidemic: The need for research and intervention strategies. Harvard Journal of African American Public Policy, 11, 13-20.

Blumstein, P. W., \& Schwartz, P. (1977). Bisexuality: Some social psychological issues. Journal of Social Issues, 33, 30-45. 
Bogle, K. A. (2008). Hooking up: Sex, dating, and relationships on campus. New York: New York University Press.

Bower, J., Gurevich, M., \& Mathieson, C. M. (2002). (Con)tested identities: Bisexual women reorient sexuality. Journal of Bisexuality, 2(2-3), 23-52.

Boykin, K. (2005). Beyond the down low: Sex, lies, and denial in Black America. New York: Avalon.

Brady, S., \& Busse, W. J. (1994). The Gay Identity Questionnaire: A brief measure of homosexual identity formation. Journal of Homosexuality, 26(4), 1-22.

Budnick, J. (2016). "Straight girls kissing"? Understanding same-gender sexuality beyond the elite college campus. Gender \& Society, 30, 745-768.

Cass, V. C. (1979). Homosexuality identity formation: A theoretical model. Journal of Homosexuality, 4, 219-235.

Cass, V. C. (1996). Sexual orientation identity formation: A western phenomenon. In R. P. Cabaj \& T. S. Stein (Eds.), Textbook of homosexuality and mental health (pp. 239-266). Washington, DC: American Psychiatric Press.

Centers for Disease Control and Prevention. (2010). HIV among African American gay and bisexual men. Retrieved from http://www.cdc.gov/hiv/risk/racia lethn ic/bmsm/facts /index .html.

Chandra, A., Copen, C. E., \& Mosher, W. D. (2013). Sexual behavior, sexual attraction, and sexual identity in the United States: Data from the 2006-2010 National Survey of Family Growth. In A. K. Baumle (Ed.), International handbook on the demography of sexuality (pp. 45-66). Dordrecht: Springer.

Cole, S. W., Kemeny, M. E., Taylor, S. E., \& Visscher, B. R. (1996). Elevated physical health risk among gay men who conceal their homosexual identity. Health Psychology, 15, $243-251$.

Collins, L. M., \& Lanza, S. T. (2010). Latent class and latent transition analysis: With applications in the social, behavioral, and health sciences. Hoboken, NJ: Wiley.

Diamond, L. M. (2003). Was it a phase? Young women's relinquishment of lesbian/bisexual identities over a 5-year period. Journal of Personality and Social Psychology, 84, $352-364$.

Diamond, L. M. (2005). "I'm straight, but I kissed a girl": The trouble with American media representations of female-female sexuality. Feminism and Psychology, 15, 104-110.

Diamond, L. M. (2008). Female bisexuality from adolescence to adulthood: Results from a 10-year longitudinal study. Developmental Psychology, 44, 5-14.

Dworkin, S. H. (2001). Working with gay, lesbian, and bisexual clients. Journal of Clinical Psychology, 57, 671-680.

Eisenberg, M. (2001). Differences in sexual risk behavior between college students with same-sex and opposite-sex experience: Results from a national survey. Archives of Sexual Behavior, 30, 575-589.

England, P., Shafer, E. F., \& Fogarty, A. C. K. (2008). Hooking up and forming romantic relationships on today's college campuses. In M. S. Kimmel \& A. Aronson (Eds.), The gendered society reader 3 (pp. 531-547). New York: Oxford University Press.

Ford, C. L., Whetten, K., Hall, S., Kaufman, J., \& Thrasher, A. (2007). Black sexuality, social construction, and research targeting "The down low" ("The DL"). Annals of Epidemiology, 17, 209-216. 
Goode, E., \& Haber, L. (1997). Sexual correlates of homosexual experience: An exploratory study of college women. Journal of Sex Research, 13, 12-21.

Hagenaars, J. A., \& Halman, L. C. (1989). Searching for ideal types: The potentialities of latent class analysis. European Sociological Review, 5, 81-96.

Hamilton, L. (2007). Trading on heterosexuality: College women's gender strategies and homophobia. Gender \& Society, 21, 145-172.

Hightow, L. B., Leone, P., Macdonald, P., McCoy, S., Sampson, L. A., \& Kaplan, A. H. (2006). Men who have sex with men and women: A unique risk group for HIV transmission on North Carolina college campuses. Sexually Transmitted Diseases, 33, 585-593.

Hoburg, R., Konik, J., Williams, M., \& Crawford, M. (2004). Bisexuality among self-identified heterosexual college students. Journal of Bisexuality, 4(1-2), 25-36.

Horowitz, J. L., \& Newcomb, M. D. (2002). A multidimensional approach to homosexual identity. Journal of Homosexuality, 42, 1-19.

Hutchins, L., \& Kaahumanu, L. (1991). Bi any other name: Bisexual people speak out. Boston: Alyson Press.

Israel, T., \& Mohr, J. J. (2004). Attitudes toward bisexual women and men: Current research, future directions. Journal of Bisexuality, 4(1-2), 117-134.

Kashubeck-West, S., \& Szymanski, D. M. (2008). Risky sexual behavior in gay and bisexual men: Internalized heterosexism, sensation seeking, and substance use. The Counseling Psychologist, 36, 595-614.

Kaufman, J. M., \& Johnson, C. (2004). Stigmatized individuals and the process of identity. Sociological Quarterly, 45, 807-833.

Kimmel, M. S. (2008). Guyland: The perilous world where boys become men. New York: Harper.

Kimmel, M., \& Plante, R. F. (2002). The gender of desire: The sexual fantasies of women and men. Advances in Gender Research, 6, 55-77.

King, J. L. (2004). On the down low: A journey into the lives of "straight" black men who sleep with men. New York: Broadway Books.

Koblin, B. A., Torian, L. V., Guilin, V., Ren, L., MacKellar, D. A., \& Valleroy, L. A. (2000). High prevalence of HIV infection among young gay men who have sex with men in New York City. AIDS, 14, 1793-1800.

Kuperberg, A., \& Padgett, J. E. (2015). Dating and hooking up in college: Meeting contexts, sex, and variation by gender, partner's gender, and class standing. Journal of Sex Research, 52, 517-531.

Kuperberg, A., \& Padgett, J. E. (2016). The role of culture in explaining college students' selection into hookups, dates, and long-term romantic relationships. Journal of Social and Personal Relationships, 33, 1070-1096.

Kuperberg, A., \& Padgett, J. E. (2017). Partner meeting contexts and risky behavior in college students' other-sex and same-sex hookups. Journal of Sex Research, 54, 52-55.

Lanza, S. T., Dziak, J. J., Huang, L., Wagner, A. T., \& Collins, L. M. (2015). LCA Stata plugin users' guide (version 1.2). University Park, PA: The Methodology Center, Penn State. Retrieved from https ://metho dolog y.psu.edu/.

Laughlin, S. (2016). Gen Z goes beyond gender binaries in new innovation group data. J. Walter Thompson Intelligence. Retrieved from https ://www.jwtin telli gence .com/2016/03/gen-z-goes-beyond-gende r-binar ies-in-new-innov ation -group -data/. 
LCA Stata Plugin (Version 1.2) [Software]. (2015). University Park: The Methodology Center, Penn State. Retrieved from https ://methodolog y.psu.edu/.

Lindley, L., Nicholson, T., Kerby, M., \& Lu, N. (2003). HIV/STI associated risk behaviors among self-identified lesbian, gay, bisexual, and transgender college students in the United States. AIDS Education and Prevention, 15, 413-429.

Ochs, R. (2007). What's in a name? Why women embrace or resist bisexual identity. In B. A. Firestein (Ed.), Becoming visible: Counseling bisexuals across the lifespan (pp. 72-86). New York: Columbia University Press.

Ochs, R., \& Deihl, M. (1992). Moving beyond binary thinking. In W. J. Blumenfeld (Ed.), Homophobia: How we all pay the price (pp. 67-75). Boston: Beacon.

Peplau, L. A., \& Finegrhut, A. W. (2007). The close relationships of lesbians and gay men. Annual Review of Psychology, 58, 405-424.

Peterson, T. L., \& Gerrity, D. A. (2006). Internalized homophobia, lesbian identity development, and self-esteem in undergraduate women. Journal of Homosexuality, 50, 49-75.

Phillips, L. (2005). Deconstructing "down low" discourse: The politics of sexuality, gender, race, AIDS, and anxiety. Journal of African American Studies, 9, 3-15.

Reiber, C., \& Garcia, J. R. (2010). Hooking up: Gender differences, evolution, and pluralistic ignorance. Evolutionary Psychology, 8, 390-404.

Rhodes, S. D., DiClemente, R. J., Cecil, H., Hergenrather, K. C., \& Yee, L. J. (2002). Risk among men who have sex with men in the United States: A comparison of an interest sample and a conventional outreach sample. AIDS Education and Prevention, 14, 141-150.

Rosario, M., Schrimshaw, E. W., Hunter, J., \& Braun, L. (2006). Sexual identity development among gay, lesbians, and bisexual youths: Consistency and change over time. Journal of Sex Research, 43, 46-58.

Ross, M. W., Essien, E. J., Wiliams, M. L., \& Fernandez-Esquer, M. E. (2003). Concordence between sexual behavior and sexual identity in street outreach samples of four racial ethnic groups. Sexually Transmitted Diseases, 30, 110-113.

Rowen, C. J., \& Malcolm, J. P. (2002). Correlates of internalized homophobia and homosexual identity formation in a sample of gay men. Journal of Homosexuality, 43, 77-92.

Rupp, L. J., Taylor, V., Regev-Messalem, S., Fogarty, A. C. K., \& England, P. (2013). Queer women in the hookup scene: Beyond the closet? Gender \& Society, 28, 212-235.

Rust, P. C. (1992). The politics of sexual identity: Sexual attraction and behavior among lesbian and bisexual women. Social Problems, 39, 366-386.

Sanday, P. R. (2007). Fraternity gang rape: Sex, brotherhood and privilege on campus. New York: New York University Press.

Savin-Williams, R. C., \& Ream, G. L. (2007). Prevalence and stability of sexual orientation components during adolescence and young adulthood. Archives of Sexual Behavior, 36, $385-394$.

Seidman, S., Meeks, C., \& Traschen, F. (1999). Beyond the closet? The changing social meaning of homosexuality in the United States. Sexualities, 2, 9-34.

Silva, T. (2017). Bud-sex: Constructing normative masculinity among rural straight men that have sex with men. Gender \& Sexuality, 31, 51-73.

Simon, W., \& Gagnon, J. H. (1986). Sexual scripts: Permanence and change. Archives of Sexual Behavior, 15, 97-120. 
Simon, W., \& Gagnon, J. H. (2003). Sexual scripts: Origins, influences, and changes. Qualitative Sociology, 26, 491-497.

Sophie, J. (1986). A critical examination of stage theories of lesbian identity formation. Journal of Homosexuality, 12, 39-51.

Szymanski, D. M., Kashubeck-West, S., \& Meyer, J. (2008). Internalized heterosexism: Measurement, psychological correlates, and research directions. The Counseling Psychologist, 36, 525-574.

Taylor, B. (1999). "Coming out" as a life transition: Homosexual identity formation and its implications for health care practice. Journal of Advanced Nursing, 30, 520-525.

Tein, J. Y., Coxe, S., \& Cham, H. (2013). Statistical power to detect the correct number of classes in latent profile analysis. Structural Equation Modeling: A Multidisciplinary Journal, 20, 640-657.

Wade, L. (2017). American hookup: The new culture of sex on campus. New York: W.W. Norton \& Co.

Walker, A. (2014a). "Our little secret": How publicly heterosexual women make meaning from their "undercover" same-sex sexual experiences. Journal of Bisexuality, 14, 194-208.

Walker, A. (2014b). "I'm not a lesbian; I'm just a freak": A pilot study of the experiences of women in assumed-monogamous other-sex unions seeking secret same-sex encounters online, their negotiation of sexual desire, and meaning-making of sexual identity. Sexuality and Culture, 18, 911-935.

Ward, J. (2015). Not gay: Sex between straight white men. New York: New York University Press.

Yost, M. R., \& Thomas, G. D. (2012). Gender and binegativity: Men and women's attitudes toward male and female bisexuals. Archives of Sexual Behavior, 41(3), 691-702.

Young, R. M., \& Meyer, I. H. (2005). The trouble with MSM and WSW: Erasure of the sexual-minority person in the public health discourse. American Journal of Public Health, $95,1144-1149$.

Zivony, A., \& Lobel, T. (2014). The invisible stereotypes of bisexual men. Archives of Sexual Behavior, 43, 1165-1176. 